\title{
SINDICALISMO E POLÍTICAS PÚBLICAS: O DISCURSO DA CUT SOBRE OS GOVERNOS FHC, LULA E DILMA
}

\author{
Karen Christina Dias da Fonseca Cilla* \\ Sidney Jard da Silva**
}

\begin{abstract}
Resumo: A Análise de Discurso (AD) disponibiliza dispositivos analíticos para que possamos avançar na compreensão crítica de um texto. A partir deste referencial teórico, o objetivo deste trabalho é identificar categorias discursivas nas resoluções dos congressos da Central Única dos Trabalhadores (CUT) em relação às políticas públicas implementadas nos governos de Fernando Henrique Cardoso, Luiz Inácio Lula da Silva e Dilma Vana Rousseff, entre o VI e XI CONCUT. Os achados de pesquisa apontam para 54 categorias discursivas sobre políticas públicas presentes nas resoluções cutistas, entre 1997 e 2012, sendo 20 referentes ao Governo FHC, 21 referentes ao Governo Lula e 13 referentes ao Governo Dilma. A posição da CUT em relação às reformas previdenciárias dos três governos é tomada como referência empírica para analisar a transição do discurso de "oposição propositiva" no Governo FHC para o discurso de "apoio crítico" nos Governos Lula e Dilma.
\end{abstract}

Palavras-chave: Análise de Discurso, Sindicalismo, Políticas Públicas, Governo FHC, Governo Lula, Governo Dilma.

Labor union and public policies: the discourse of CUT towards the governments of FHC, Lula, and Dilma

Abstract: Discourse Analysis (AD) provides analytical devices to move on a discerning understanding of a text. From this theoretical framework, the present study is aimed to identify discursive categories in the resolutions of meetings from VI to XI CONCUT conference held by the labor union CUT (Central Única dos Trabalhadores) in relation to public policies implemented in the governments of Fernando Henrique Cardoso, Luiz Inácio Lula da Silva, and Dilma Vana Rousseff. The research findings point to

* Mestre em Ensino, História e Filosofia da Ciência e da Matemática pela Universidade Federal do ABC (UFABC).

** Professor do Centro de Engenharia, Modelagem e Ciências Sociais Aplicadas da Universidade Federal do ABC (CECS/UFABC).

Recebido em: 30/01/2014 - Aceito em: 03/09/2015. 
54 discursive categories of public policies present in CUT resolutions from 1997 to 2012; 20 referring to the FHC government, 21 to the Lula government, and 13 to the Dilma government. CUT's standpoint in relation to the social security reforms carried out during the three terms is taken as empirical reference to analyze the transition from the discourse of "purpose opposition" in the FHC government to the discourse of "critical support" in Lula and Dilma governments.

Keywords: Discourse Analysis, Union Trade, Public Policies, FHC Government, Lula Government, Dilma Government.

El sindicalismo y la política pública: el discurso de la CUT en el gobierno FHC, Lula y Dilma

Resumen: El Análisis del Discurso (AD) proporciona dispositivos de análisis para que podamos avanzar en la comprensión crítica de un texto. A partir de este marco teórico, el objetivo de este estudio es identificar las categorías discursivas en las resoluciones del congreso de la Central Unitaria de Trabajadores (CUT), en relación con las políticas públicas implementadas en el gobierno de Fernando Henrique Cardoso, Luiz Inácio Lula da Silva y Dilma Vana Rousseff, entre VI y XI CONCUT. Los resultados de la investigación apuntan a 54 categorías discursivas de las políticas públicas en las presentes resoluciones CUT entre 1997 y 2012, 20 para el gobierno de Cardoso, 21 para el gobierno de Lula y de 13 para el gobierno de Dilma. La posición de la CUT en relación con las reformas de las pensiones de los tres gobiernos se toma como referente empírico para analizar la transición del discurso de "oposición decidida" en el gobierno FHC al discurso de "apoyo crítico" en los gobiernos de Lula y Dilma.

Palabras-clave: Análisis del Discurso, el sindicalismo, la política pública, el gobierno FHC, del gobierno Lula, el gobierno Dilma.

\section{Introdução $^{1}$}

Na Análise de Discurso (AD) o discurso não é apenas fala, palavras ou imagens, ele é um objeto construído pelo analista, um produto da análise. Ao encararmos um texto sob essa perspectiva, é possível relacionar o documento a sua historicidade e tratá-lo não apenas como algo naturalizado, mas sim como a manifestação concreta de um discurso que está relacionado a uma determinada formação discursiva. ${ }^{1}$ Os autores agradecem ao Conselho Nacional de Desenvolvimento Científico
e Tecnológico (CNPq) pelo suporte técnico e financeiro. 
Deste modo, a AD disponibiliza dispositivos teóricos e analíticos para que possamos avançar na compreensão de um texto ou de um conjunto de textos. No caso da AD de inspiração francesa, que surgiu a partir dos estudos de Michel Pêcheux, elaborados principalmente nas décadas de 70 e 80 , a abordagem teórica traz considerações relevantes sobre os contextos epistemológicos em que se encontravam as ciências humanas na França desde a década de 50 .

Além de Pêcheux, a AD francesa também congrega as teorias desenvolvidas por Foucault e Bakthin. Embora cada um desses autores tenha formulado seus conceitos com finalidades distintas, há em comum a rejeição à concepção estruturalista que retira da análise a dimensão histórica do sujeito (SARGENTINI, 2005).

Foucault, ao problematizar a história apontando suas continuidades e sua dispersão, trouxe à tona a questão do "descentramento" do sujeito e do sentido nas práticas discursivas que constituem os saberes. A leitura que faz Bakhtin, principalmente na década de 80 , levou a AD a voltar-se para as questões do sujeito e do sentido considerando os conceitos de heterogeneidade e de alteridade. (GREGOLIN et al., 2001, p.30).

O conceito de discurso é disputado pelos autores da AD. Foucault (1973) o define como um conjunto de enunciados controlados pertencentes a uma mesma formação discursiva ${ }^{2}$. Maingueneau (2000, p. 55), analisando as ideias bakthinianas, diz que para interpretar qualquer enunciado é necessário relacionálo a muitos outros, isso porque o discurso só adquire sentido se estiver inserido em um universo de outros discursos.

Orlandi (2010) defende que, para a $\mathrm{AD}$, o discurso não é meramente transmissão de informações ou comunicação. Segundo a autora, o discurso é uma produção de sentidos dentro de um determinado contexto social, histórico e em certas condições de

2 Para Foucault (1987), na Arqueologia do Saber, o discurso se constitui na dispersão dos textos, não na unidade. O texto possui historicidade também porque se relaciona com formações discursivas já cristalizadas historicamente. 
produção (ORLANDI, 2008) ${ }^{3}$. Deste modo, a AD busca remeter o texto ao discurso trazendo à tona as relações deste com a ideologia e a história. O texto é o que nos dá o acesso ao discurso, por isso a análise não se detém no escrito. Da mesma forma, a análise não se detém no discurso porque este não pode ser concebido fora do sujeito e nem da ideologia que o constitui.

Pêcheux e Bakhtin concordam que a ideologia não está no nível do inconsciente, mas sim é oriunda das lutas de classe em um processo histórico dialético. Bakhtin, através de seu conceito de signo ideológico (BAKHTIN, 2006) evidencia a relação entre a infra-estrutura e a superestrutura desenvolvidas por Marx. Para este autor todo significado dado além da natureza do objeto é ideológico. Assim, este signo ideológico, no palco da luta de classe, reproduz e distorce a realidade material, tendo seu significado disputado entre interesses contraditórios.

Deste modo, a palavra não terá significado fora da ideologia, pois na sua função de signo é um fenômeno ideológico por excelência, elemento essencial de toda criação ideológica (BAKHTIN, 2006).

Nesta perspectiva, Orlandi também afirma que o sentido das palavras depende das posições ideológicas daqueles que as utilizam. As formações ideológicas nas quais essas posições se inscrevem é que dão sentido às palavras. A ideologia também produz outros efeitos, tais como dar sentido a relação do sujeito com a língua e com a história, tornar possível a relação linguagem/ mundo/pensamento e constituir o sujeito.

Deste modo, a AD trabalha com uma noção particular de sujeito, sendo este ao mesmo tempo autônomo e submisso. Atravessado tanto pela ideologia quanto pelo inconsciente, este

\footnotetext{
${ }^{3}$ Neste trabalho, a Análise do Discurso desenvolvidas por Eni Orlandi (ORLANDI, 2008, 2009 e 2010) serão desenvolvidas e utilizadas para propor uma chave de entendimento do discurso sindical sobre as políticas públicas dos governos Fernando Henrique, Lula da Silva e Dilma Rousseff. Os escritos da professora Eni Orlandi foram privilegiados porque a autora é uma importante interlocutora da AD francesa no Brasil.
} 
sujeito acredita ser a origem do sentido que enuncia, contudo isso é uma dupla ilusão porque seu discurso faz parte de um processo e de uma formação discursiva na qual se insere, mas sobre a qual não possui controle. Assim, na constituição do sujeito do discurso, ele é interpelado pela ideologia, mas se acredita livre, ao mesmo tempo em que é dotado de inconsciente, mas se acredita conduzido pelo consciente.

Quando o sujeito fala a partir da posição de sindicalista, por exemplo, o sentido daquilo que ele diz deriva da posição que ocupa. Não é só o indivíduo falando, mas também é a sua posição, e todo o interdiscurso a ela relacionado, que não pode ser totalmente apreendido pelo próprio sujeito, mas que significa e dá identidade ao que é dito.

Desta forma, nem os sujeitos nem os sentidos são completos, estão em processo de constituição. Este processo tanto pode ser aberto, quanto pode conduzir a certa estabilização dos sentidos. Mas mesmo que os sentidos possam se estabilizar, a $\mathrm{AD}$ não se compromete com uma busca por um sentido verdadeiro, ao contrário, propõe que se explicite os processos de identificação dos sujeitos com suas filiações de sentidos e suas memórias.

Se os sentidos se deslocam e não se estabilizam temos o que Orlandi (2010) chama de efeitos metafóricos, que são transferências onde ocorre a substituição conceitual, um deslizamento de sentido que é a base da constituição do próprio sentido e do sujeito. O efeito metafórico é parte do funcionamento discursivo, "é lugar da interpretação, da ideologia, da historicidade" (p. 80).

Contudo, não é apenas no efeito metafórico ou na estabilização de sentidos que a ideologia, a historicidade e a interpretação encontram lugar, mas também no não-dito do discurso. Em todo dizer há necessariamente um não-dizer que o sustenta. O silêncio também é uma forma de não-dizer, que pode tanto ser um recuo necessário para que o sentido possa significar e possa ser outro (silêncio fundador) quanto uma política do silêncio onde há proibição de alguns dizeres (silêncio local, censura) ou ainda uma palavra que acaba por apagar outras palavras ao falar por elas (silêncio constitutivo). 
Mesmo atentando para estas sutilezas dos discursos e dos sentidos, a $\mathrm{AD}$ ainda considera que todo discurso é um objeto inesgotável. Deste modo, a análise em momento algum pretende exaurir o objeto, mas apenas atender aos objetivos que se colocou. É justamente nesta perspectiva que se coloca o presente trabalho, seu objetivo é identificar as principais categorias discursivas presentes nas resoluções dos congressos da Central Única dos Trabalhadores (CUT), entre 1997 e 2012, em relação às políticas públicas dos governos de Fernando Henrique Cardoso (1995-2002), Luiz Inácio Lula da Silva (2003-2010) e Dilma Vana Rousseff (2011).

\section{Análise do discurso cutista sobre os governos FHC, Lula e Dilma}

A Análise de Discurso forma um quadro teóricoepistemológico complexo e denso. A cada análise é praticamente inevitável colocar em questão a natureza de alguns dos seus pressupostos e conceitos, bem como redefinir seus limites. Não obstante, isto contribui para o desenvolvimento de uma disciplina de interpretação que leva em conta tais desafios na construção de seu objeto de pesquisa e estabelece certos procedimentos de análise que marcam o território conceitual da AD.

Inicialmente, para realizarmos a Análise de Discurso de um texto ou grupo de textos, é necessário identificar trechos, frases ou palavras que expressem os sentidos do documento em apreciação. Depois de identificados, tais sentidos podem ser categorizados a partir das similaridades entre eles. Deste modo, o analista pode propor categorias que agrupem as unidades de sentido semelhantes entre si para desenvolver a sua observação (ORLANDI, 2010).

Ao analisarmos os discursos da CUT, expressos nos documentos do VI ao XI CONCUT, buscamos identificar suas principais categorias, com a intenção de levantar os sentidos que circulam nos discursos da Central em relação às políticas públicas dos governos de Fernando Henrique Cardoso (1995-2002), Luiz Inácio Lula da Silva (2003-2010) e Dilma Vana Rousseff (2011-). 
Esta busca, entretanto, não foi aleatória, nos concentramos em três eixos principais de análise:

- Como a CUT caracteriza o governo

- Como a CUT caracteriza as ações do governo

- Como a CUT reage ao governo

A partir destes três eixos, analisamos os textos das cinco resoluções de congressos cutistas realizados entre 1997 e 2012 e propusemos 54 categorias analíticas, sendo 20 referentes ao Governo FHC, 21 referentes ao Governo Lula e 13 referentes ao Governo Dilma ${ }^{4}$ Abaixo (Quadros 1, 2 e 3), apresentamos as categorias divididas pelos governos e eixos, respectivamente, e, a seguir, o detalhamento desta categorização.

${ }^{4}$ O VI e o VII CONCUT para o governo de Fernando Henrique Cardoso (19952002), o VIII, o IX e o X CONCUT para o governo de Luiz Inácio Lula da Silva (2003-2010) e o XI CONCUT para o governo de Dilma Vana Rousseff (2011-). O número menor de categorias discursivas para o Governo Dilma deve-se a realização de apenas um congresso cutista em seu mandato.

Idéias - Rev. Inst. Filos. Ciênc. Hum. UNICAMP, v.6, n.2, p. 101-133, jul/dez. 2015 
Sindicalismo e políticas públicas...

\section{QUADRO 1 - Como caracteriza o governo}

\begin{tabular}{|c|c|c|}
\hline FHC & Lula & Dilma \\
\hline - Mantém a & $\begin{array}{c}\text { - Representa o projeto } \\
\text { democrático da esquerda } \\
\text { brasileira }\end{array}$ & \\
estabilização & - Representa os anseios & \\
da maioria da sociedade & brasileira & \\
- Atende as diretrizes & - Caminho para & - Continuidade do \\
internacionais & a superação do & projeto democrático do \\
- Comprometido & governo anterior \\
com as reformas & neoliberais & - Possibilita a construção \\
de uma nova sociedade & privatista da gestão \\
pública
\end{tabular}

Noque se refere à caracterização dogoverno, o discurso cutista afirma que o mandato de Fernando Henrique Cardoso (1995-2002) esteve comprometido com as diretrizes estabelecidas no Consenso de Washington. Deste modo, acabou por privilegiar os círculos produtivos e financeiros vinculados ao capital internacional. O Governo FHC seria orientado pelos princípios básicos do neoliberalismo, como a flexibilização e precarização das relações de trabalho, a desregulamentação da economia, a privatização 
das empresas estatais e a redução dos direitos conquistados pelos trabalhadores. Ainda segundo a Central, ao privatizar as empresas públicas, o Governo FHC também teria sucateado os serviços públicos e privatizado suas responsabilidades sociais. Assim, teria ampliado a exclusão social e atacado os direitos sociais dos trabalhadores.

A CUT considera que o que o Governo FHC foi eleito para ser representante das elites tradicionais brasileiras, e, por isso, teria sido benevolente e manipulado por elas para implementar uma modernização conservadora e limitada. Por fim, o Governo Fernando Henrique Cardoso teria mantido artificialmente as diretrizes de seu programa de estabilização, mesmo sob a pressão contrária de setores da sociedade que demandavam a flexibilização da política econômica.

O governo de Luiz Inácio Lula da Silva (2003-2010), por sua vez, representaria o caminho de superação da política neoliberal. Um núcleo de esquerda, forjado na luta contra a ditadura e na resistência ao neoliberalismo, com uma plataforma assentada na inclusão social. $O$ próprio Lula personificaria um projeto democrático popular que teria o compromisso de lutar pela conquista de uma sociedade soberana e justa. Nessa perspectiva, uma eventual derrota deste governo representaria o fracasso do próprio projeto alternativo da esquerda para o Brasil.

O discurso da CUT ainda assevera que o Governo Luiz Inácio Lula da Silva representava os anseios de amplos setores da sociedade, em particular da classe trabalhadora. O Governo Lula teria tornado maiores as possibilidades de construção de uma sociedade mais justa, igualitária e democrática.

As resoluções cutistas também destacam que o Governo Lula ampliou as relações e negociações com os trabalhadores, de uma forma transparente e com a merecida atenção. Ampliou os canais de diálogo e fortaleceu a democracia. Segundo a Central, esta foi uma conquista histórica dos setores que historicamente lutaram pela democratização do Estado e das relações de trabalho no Brasil. 
Neste sentido, a CUT afirma que o seu campo político é o mesmo do Presidente Luiz Inácio Lula da Silva. A continuidade do projeto democrático popular do governo constituiria um cenário favorável para o alcance dos ideais cutistas que rejeitavam a agenda conservadora do neoliberalismo.

Não obstante, as resoluções dos congressos cutistas também apontavam que um dos grandes desafios do Governo Lula era superar a "herança maldita" deixada pelo Governo FHC, principalmente no que tange à política macroeconômica. Os juros altos, por exemplo, provocavam efeitos nocivos para a sociedade como um todo e para os trabalhadores em particular.

Por fim, o discurso cutista também reconhecia as limitações do Governo Lula, entre as quais destacava: I) o cenário de crise mundial; II) a herança deixada por FHC e III) a baixa representatividade da esquerda no Congresso Nacional. Tais constrangimentos impediam que este Governo efetivasse concretamente as bandeiras trabalhistas e sindicais que historicamente compartilhou com CUT.

No que tange ao governo Dilma, a CUT o caracteriza como continuidade do governo anterior (Lula), pela manutenção dos programas sociais, da política de valorização do salário mínimo e das concessões de benefícios da Previdência Social. Outro ponto de continuidade, este criticado pelo discurso cutista, é a permanência da lógica privatista da gestão pública, através de políticas de concessões, terceirizações, privatizações de gestão nas áreas da saúde e das Parcerias Público-Privadas (PPPs). Nesta perspectiva, a "herança maldita" do Governo FHC teria perpassado o Governo Lula e alcançado o Governo Dilma.

Como ponto de ruptura positivo, comparativamente aos presidentes Fernando Henrique e Lula da Silva, a CUT aponta o fato da Presidente Dilma Rousseff fortalecer quantitativa e qualitativamente o sistema financeiro público através da redução do poder do capital financeiro. O fortalecimento do Banco Central como não subordinado aos bancos privados, direcionado para a defesa da moeda, para o combate a especulação cambial e a agiotagem foram considerados passos de extrema importância neste sentido. 


\section{QUADRO 2 - Como caracteriza as ações do governo}

\begin{tabular}{|c|c|c|}
\hline FHC & Lula & Dilma \\
\hline $\begin{array}{c}\text { - Política econômica } \\
\text { insustentável } \\
\text { - Legitima os ajustes } \\
\text { neoliberais } \\
\text { - Compra apoio } \\
\text { político } \\
\text { - Reforma Agrária } \\
\text { insuficiente } \\
\text { - Nega o direito ao } \\
\text { trabalho } \\
\text { - Desmonta o Estado } \\
\text { - Cria grandes custos } \\
\text { nacionais } \\
\text { - Criminaliza a } \\
\text { resistência ao governo }\end{array}$ & $\begin{array}{c}\text { - Contraditório em sua } \\
\text { práxis } \\
\text { - Implanta o controle } \\
\text { social sobre o Estado } \\
\text { - Paralisa o desmonte } \\
\text { do Estado } \\
\text { - Atende reivindicações } \\
\text { dos trabalhadores } \\
\text { - Ineficaz e fraco no } \\
\text { tratamento de algumas } \\
\text { questões } \\
\text { - Atende demandas das } \\
\text { elites }\end{array}$ & $\begin{array}{l}\text { - Empenho na redução } \\
\text { da pobreza } \\
\text { - Precarização do } \\
\text { trabalho e dura política } \\
\text { salarial em alguns } \\
\text { setores } \\
\text {-Dinamiza as } \\
\text { economias dos estados } \\
\text { e municípios } \\
\text { - Reduz o poder do } \\
\text { capital financeiro }\end{array}$ \\
\hline
\end{tabular}

O discurso da CUT aponta para a insustentabilidade da política econômica do Governo FHC de deslocar as pressões sobre a valorização cambial e os juros elevados, através de incentivos às exportações, apoio às pequenas empresas, redução do Custo Brasil e mecanismos temporários de proteção aos setores industriais mais afetados pela concorrência internacional. Nesta perspectiva, a política econômica favoreceria a abertura ao capital estrangeiro, que também era responsável pela manutenção do financiamento do déficit comercial e da valorização do real. No entender da Central, no longo prazo, tais medidas inviabilizariam o desenvolvimento do país.

No discurso cutista, o Governo Fernando Henrique fez uma inserção subordinada da economia à lógica neoliberal e procurava legitimá-la. Algumas dessas ações legitimadoras foram a drástica redução da inflação através do Plano Real e a desnacionalização da economia através das privatizações. Outro exemplo estaria na agricultura, que recebeu financiamento do setor público apenas 
quando se adequou aos padrões internacionais colocando os agricultores a mercê dos mercados globais e a atividade agrária refém do receituário neoliberal. Neste último caso, a CUT ainda assevera que as definições políticas do Governo FHC sobre as questões agrárias foram frutos de pressões dos latifundiários, $\mathrm{o}$ que reduziu a reforma agrária ao atendimento de interesses dos grandes fazendeiros e não dos trabalhadores rurais.

Em síntese, o discurso da CUT aponta que as ações do governo de Fernando Henrique Cardoso teriam imposto grandes custos nacionais e sociais para o Brasil. Ao beneficiar os grandes bancos e o capital especulativo teria deixado de investir no social, aprofundando o desemprego, a fome e a miséria. Além disso, ao transferir as estatais para o grande capital, o Governo FHC teria desorganizado os serviços públicos, reduzido os investimentos públicos e os gastos sociais, ampliado a exclusão social e enfraquecido o poder de intervenção, regulação e dinamização do Estado.

O discurso cutista também considera que a reforma trabalhista proposta pelo Governo FHC foi um retrocesso nas relações entre capital e trabalho no país, a ponto de negar o próprio direito ao trabalho. Além disso, a CUT também afirma que os setores sociais que resistiram à política neoliberal foram criminalizados pelo Governo Fernando Henrique que reagiu monopolizando as instituições, as comunicações e as decisões políticas.

Por fim, o discurso cutista também questiona a própria legitimidade política do governo de Fernando Henrique Cardoso que, segundo a Central, comprava apoio político para aprovar suas propostas no Congresso Nacional. Como exemplo cita o caso da aprovação da Emenda Constitucional n.o 16, de 04 de junho de 1997, que autorizou o instituto da reeleição e a distribuição de cargos e favores para os parlamentares que votaram a favor do Executivo. Segundo a CUT, esta prática denunciava a crise moral e política que vivia o Brasil durante o governo de FHC.

No que se refere à caracterização do Governo Lula, por sua vez, o discurso cutista afirma que este paralisou o desmonte do Estado que vinha ocorrendo durante o Governo FHC e recuperou 
sua capacidade enquanto gestor e executor de políticas públicas. Segundo a CUT, o Governo Lula propôs a criação de diferentes espaços de participação da sociedade na condução das políticas públicas, tornando possível uma efetiva democratização do Estado através de uma política mais participativa e de maior controle social. Como exemplo destaca o fato de que as centrais sindicais passaram a ter maior representatividade institucional e a criação das Conferências Nacionais, que inauguraram uma agenda deliberativa e de debates sobre vários temas, bem como uma nova relação entre Estado e movimentos sociais.

A CUT ainda afirma que o Governo Lula atendeu, em certa medida, as reivindicações e mobilizações dos trabalhadores e da própria Central, tais como a valorização do salário mínimo e a representatividade legal das centrais sindicais nas discussões do governo sobre questões relativas ao trabalho.

No entanto, a CUT considera que o Governo Lula também expôs suas contradições. Segundo a Central, o governo foi fraco e ineficaz para enfrentar importantes problemas herdados dos governos anteriores, tais como a questão da violência na cidade e no campo e a política fiscal, que teve sinalizações positivas de mudança, porém tímidas. A CUT ainda afirma que o Governo Lula também procurou atender as demandas do mercado. Como exemplo, cita a continuidade da reforma da previdência iniciada no Governo FHC, que retirou direitos históricos dos servidores públicos.

Sobre o Governo Dilma, o discurso cutista aponta o empenho na redução da pobreza como uma ação de continuidade do Governo Lula, através da manutenção dos programas sociais como BolsaFamília e da extensão de novos benefícios da Previdência Social também aos trabalhadores do campo.

Ainda segundo a CUT, as obras de infraestrutura no interior do país realizadas pelo Governo Dilma geraram novos postos de trabalho, ampliaram o poder de compra das populações rurais e dinamizaram, de modo geral, a economia dos estados e municípios.

Já as ações levadas a termo pelo governo de Dilma Rousseff relacionadas à Copa do Mundo receberam duras críticas, 
principalmente o Projeto de Lei 2330/2011 (transformado na "Lei Geral da Copa", Lei n. o 12.663/2012) e a consequente precarização das relações de trabalho que ocorre em eventos desta magnitude.

A CUT também criticou duramente a política salarial para os servidores públicos federais do Judiciário e Ministério Público, já que o Governo Dilma não cumpriu o acordo de reajuste salarial a estes servidores. Segundo a Central, a presidente manteve uma postura discriminatória no tratamento desta questão.

Por fim, a mudança do governo de Dilma Rousseff em relação ao do seu antecessor, Lula da Silva, foi ressaltada como positiva no que tange ao que a CUT chama de "enfrentamento" e "redução" do poder do capital financeiro, através da afirmação do sistema financeiro público e do fortalecimento do Banco Central. As ações implementadas pelo governo como a redução dos juros, que se iniciou pelos bancos públicos, e forçou os bancos privados a fazerem o mesmo, seriam indícios de uma nova orientação para política econômica.

\section{QUADRO 3 - Como reage ao governo}

\begin{tabular}{|c|c|c|}
\hline FHC & Lula & Dilma \\
\hline & - Organiza os trabalhadores & - Resgata o papel e \\
- Apresenta & para as negociações & centralidade do Estado \\
alternativas & - Entra na disputa pela & - Busca um novo \\
paradigma para as \\
- Age na defensiva & hegemonia política & relações de trabalho \\
- Pressiona e exige & - Apoia políticas & - Constrói outro \\
mudanças & compartilhadas & paradigma econômico \\
- Propõe uma & compartilínadas & - Mantém a luta contra \\
Greve Geral & - Denuncia ações contrárias & a desigualdade \\
- Denuncia as & ao governo & - Contra a entrada do \\
irregularidades & - Propõe um projeto de & capital estrangeiro \\
- Combate & superação das heranças & na educação superior \\
o projeto & neoliberais & brasileira \\
hegemônico & - Coloca sua autonomia à & - Exige do governo \\
& frente do governo & medidas contra a crise \\
& \multicolumn{2}{|c}{} \\
\hline
\end{tabular}


A CUT coloca, em seu discurso, que a estabilidade econômica alardeada no Governo FHC acabou por dificultar a ação sindical, pois o colocou na defensiva. Neste sentido, a Central propôs a organização de uma ofensiva contra o projeto hegemônico de FHC, através da luta contra a guerra fiscal, a busca por espaço na mídia, a mobilização e organização dos trabalhadores.

A CUT também convocou outros setores democráticos e populares para pressionarem o governo exigindo abertura, transparência, participação popular, mudanças e a reorientação da política econômica, direcionando-a ao crescimento com equidade social, ambiental e regional.

Uma das formas de reação colocadas a termo pela CUT foi a denúncia do colapso das finanças municipais provocado pela política econômica do Governo FHC e a luta pela instalação de uma Comissão Parlamentar de Inquérito (CPI) para investigar o envolvimento de pessoas ligadas ao governo, incluindo o próprio presidente, em atos de corrupção. Para tal investiu nas disputas eleitorais municipais e aprofundou as investigações das denúncias. A CUT decidiu ainda mobilizar os trabalhadores de várias áreas para uma greve geral contra as ações do governo de Fernando Henrique Cardoso.

As ações da CUT em relação ao Governo FHC não se limitaram a uma pauta essencialmente reativa, segundo o discurso a Central, uma das formas de reação também foi apresentar alternativas ao modelo de desenvolvimento econômico. Para tanto, a CUT se propôs a formalizar um programa nacional para substituir a orientação da política econômica neoliberal.

No que se refere ao Governo Lula, uma das reações propostas no discurso da CUT foi intensificar a organização dos trabalhadores desde os locais de trabalho e também nos processos de negociação coletiva. A luta dos trabalhadores devia estar em sintonia com a luta mais geral do governo, rumo à reconstrução nacional e por um novo modelo de desenvolvimento. Para tanto, também foi necessário intensificar a formação sindical dos dirigentes frente a um governo que trouxe à discussão reivindicações históricas dos trabalhadores, isto porque a construção de espaços democráticos 
de debates e a eleição de Lula exigiram da CUT um novo patamar de organização.

Ainda segundo o discurso cutista, uma das reações propostas foi organizar os trabalhadores para as lutas pela disputa da hegemonia política, ideológica e cultural para constituir uma nova sociedade. A luta não poderia ferir a autonomia e a liberdade sindical, mas deveria traçar uma estratégia de união com outras entidades do movimento social no Brasil.

A CUT também propôs que as políticas do Governo Lula que correspondessem aos compromissos assumidos em campanha recebessem o apoio da Central. Para tanto, seria necessário mobilizar amplas massas em defesa das mudanças propostas pelo novo governo, desde que elas fossem coincidentes com as reivindicações da classe trabalhadora. Uma das reações defendidas no discurso cutista seria a de denunciar as "artimanhas" das elites contra o Presidente Luiz Inácio Lula da Silva.

No discurso cutista era necessário impedir que as reformas e ações do Governo Lula tivessem um caráter regressivo. Para tanto, era importante que as mudanças viessem a romper com as heranças do período FHC. Não obstante, a aliança com setores conservadores da sociedade não poderia criar um antagonismo da CUT com o governo. Ao contrário, a Central deveria travar uma disputa sobre o caráter político das reformas em curso, defendendo uma maior participação social e das entidades sindicais na discussão das propostas do governo.

Por fim, apesar do apoio declarado ao governo de Luiz Inácio Lula da Silva, o discurso cutista foi pautado pela necessidade de preservar a sua independência e reafirmar sua autonomia frente aos partidos políticos e ao governo aliado.

No Governo Dilma, a CUT se posiciona de modo a estabelecer novos paradigmas, principalmente na política econômica e trabalhista. No que tange ao novo paradigma trabalhista, as ações propostas vão desde incrementos das políticas de garantia de emprego, o princípio da rotatividade para o pagamento do segurodesemprego, o cumprimento dos acordos firmados até a criação de um Sistema Democrático de Relações de Trabalho (SDRT), que 
tenha como norte a defesa do desenvolvimento sustentável e do "trabalho decente".

Além disso, a criação de normas, por parte do Governo Federal, para fiscalização e controle dos Órgãos Gestores de Mão de Obra (OGMO), respeito aos acordos e datas-base são parte da pauta de reivindicações da Central frente ao governo de DilmaRousseff.

Neste ínterim, a CUT pede a retirada do Congresso Nacional de Projetos de Leis contrários aos interesses dos servidores públicos, tais como o PL 549/09, que trata de congelamento do salário dos servidores; o PLP 248/98, que trata de demissão de servidor por suposta insuficiência de desempenho; e o PL 1992/07, que trata da criação do regime de previdência complementar para os servidores públicos 5 .

A Central também defende que um novo paradigma econômico deve ser construído através da viabilização da Conferência Nacional do Sistema Financeiro, para propor soluções e caminhos alternativos na política econômica, debater o papel do Sistema Financeiro Nacional, do Banco Central do Brasil, do Conselho Monetário Nacional, dos bancos públicos e dos fundos de pensão.

Além disso, a CUT também defende o controle social e a participação popular para decidir a destinação dos recursos provenientes da exploração do patrimônio natural do petróleo, bem como a criação de um fundo social com estes recursos para fomentar investimentos na saúde, previdência, educação pública, habitação popular, reforma agrária e a agricultura familiar sustentável ${ }^{6}$.

\footnotetext{
${ }^{5}$ Sobre a criação da Fundação de Previdência Complementar do Servidor Público Federal (Funpresp), ver Jardim e Jard da Silva, 2015.

${ }^{6}$ Segundo a Central, também é necessário implantar o marco regulatório do ensino superior privado, para finalizar a entrada de investimento financeiro estrangeiro no ensino superior que já está $70 \%$ sob controle da inciativa privada.
} 
Com essas ações o discurso cutista coloca como possível o resgate do papel e da centralidade do Estado, que, fortalecido, não precisaria recorrer às privatizações e terceirizações, retirando do setor privado, deste modo, a intermediação do acesso aos direitos. Um Estado forte, porém não autoritário é o que defende a Central, que não precarize as relações de trabalho e que respeite as práticas sindicais, a legislação trabalhista e a previdenciária.

Por fim, mesmo reconhecendo o cenário econômico do Governo Dilma como favorável, a CUT aponta que as desigualdades sociais ainda persistem. Por consequência, a luta por suas bandeiras históricas precisa ser mantida. Para a Central é preciso que o centro das políticas públicas seja o combate aos fatores que favorecem a continuidade da discriminação social e da desigualdade de classes.

\section{Análise do discurso cutista sobre a previdência}

Assim como nas seções anteriores, ao analisarmos os discursos da CUT, expressos nas resoluções do VI ao XI CONCUT, buscamos identificar suas principais categorias, com a intenção de levantar os sentidos que circulam nos discursos da Central em relação às mudanças implementadas na área de previdência social pelos governos Fernando Henrique Cardoso, Luiz Inácio Lula da Silva e Dilma Vana Rousseff.

Neste caso, nos concentramos em dois eixos principais:

- Como a CUT caracteriza a reforma da previdência

- Como a CUT reage à reforma da previdência

A partir destes dois eixos, analisamos os textos das resoluções cutistas e propusemos ao todo 18 categorias, sendo 8 referentes ao Governo FHC, 7 referentes ao Governo Lula e 3 referentes ao Governo Dilma ${ }^{7}$. A seguir, apresentamos estas categorias em

\footnotetext{
${ }^{7}$ Conforme destacamos anteriormente, o número menor de categorias para o governo de Dilma Rousseff se deve a realização de apenas um congresso da CUT durante o seu primeiro mandato.
} 
seus respectivos eixos e um breve detalhamento da classificação proposta.

\section{QUADRO 4 - Caraterização da Reforma da Previdência}

\begin{tabular}{|c|c|c|}
\hline Governo FHC & Governo Lula & Governo Dilma \\
\hline - A política neoliberal & & \\
desregulamentou a & & \\
Previdência Social, & & \\
suprimindo direitos & - A Reforma da & \\
previdenciários. & Previdência manteve a & \\
- A Reforma da & retirada de direitos dos & \\
Previdência foi & trabalhadores & \\
conduzida por & - debate durante & - Toma a expansão \\
decretos, sem debate, & da previdência \\
a custas de favores e & a Reforma da & complementar como \\
propinas. & Previdência foi restrito & uma realidade. \\
- As reformas como & - A Reforma & \\
as da Previdência & continuou sem & \\
ampliaram os espaços & resolver os problemas & \\
de acumulação de & existentes no sistema & \\
capital & previdenciário. & \\
- A Reforma da & & \\
Previdência foi & & \\
orientada por & & \\
organizações & & \\
internacionais. & & \\
& & \\
\end{tabular}

O discurso cutista referente à reforma da previdência do Governo FHC assevera que a política neoliberal desregulamentou a previdência social suprimindo direitos previdenciários dos trabalhadores. Segundo a CUT, a expansão dos investimentos externos diretos nos países em desenvolvimento foi acompanhada da desregulamentação dos sistemas previdenciários. No Brasil, até o final dos anos 80 , a previdência estava submetida à regulação 
do Estado, que restringia a participação do capital externo. Com a abertura ao capital estrangeiro feita no Governo FHC, a regulamentação dos direitos previdenciários passou a estar subordinada aos interesses de grupos de investidores.

O discurso da Central ainda afirma que as organizações financeiras internacionais impuseram condições para que os países em desenvolvimento se inserissem na economia globalizada. Estas condições correspondiam a um modelo de estabilização que envolvia o corte dos gastos sociais na previdência, a privatização dos serviços públicos e reformas que retiraram direitos dos trabalhadores. FHC ao adotar este modelo de estabilização sinalizou seu compromisso com as políticas apoiadas por estas instituições e pelo Consenso de Washington.

Nesta perspectiva, a reforma da previdência, bem como outras reformas empreendidas por FHC, ampliaram os espaços de acumulação do capital, deixando as portas abertas ao capital estrangeiro. Segundo a CUT, ao cortar gastos públicos e privados com a previdência, a acumulação e a concentração do capital teria sido favorecida.

No que se refere ao processo de aprovação da reforma da previdência, a CUT afirma que tais processos se deram através de processos legislativos que impediram o debate sobre o tema. Segundo a Central, o Governo FHC conquistou o apoio da maioria no legislativo através do loteamento de cargos públicos, o que prejudicou um debate maior e garantiu a aprovação de medidas prejudiciais aos trabalhadores, como o fator previdenciário.

Já no tocante ao governo de Luiz Inácio Lula da Silva, a CUT considera que a reforma da previdência manteve a lógica da retirada de direitos dos trabalhadores, isto é, não voltou atrás nas medidas já tomadas anteriormente no Governo FHC. A Central ainda considera que a proposta de reforma do Governo Lula foi fruto de um debate restrito ao âmbito do Conselho de Desenvolvimento Econômico e Social (CEDES) e com os 27 governadores da federação, mas sem um efetivo processo de negociação com as entidades representativas dos trabalhadores. 
O discurso cutista assevera ainda que a reforma da previdência do Governo Lula não conseguiu resolver os problemas estruturais da previdência social brasileira, especialmente no que se refere ao regime próprio de previdência dos servidores públicos. Neste caso, em particular, a Central se posicionou contra a criação da Fundação de Previdência do Servidor Público Federal (Funpresp).

Ao contrário do que ocorreu nos governos de Fernando Henrique Cardoso e de Luiz Inácio Lula da Silva, o governo de Dilma Vana Roussef não promoveu uma reforma do sistema previdenciário. Não obstante, teve um papel de fundamental importância na criação da previdência complementar do setor público, a qual aguardava sua regulamentação desde a reforma previdenciária de 2003.

Neste caso, considerando a expansão da previdência complementar como uma consequência direta das reformas realizadas nos governos anteriores, a CUT limitou-se a apresentar um discurso em defesa da "Previdência Pública Nacional", das conquistas e direitos dos trabalhadores e pelo controle social da previdência (XI CONCUT, 2012, p. 36). A Central ainda se posicionou contrariamente à política de desoneração da contribuição previdenciária na folha de pagamento e reafirmou sua posição contrária ao Fator Previdenciário e à implementação de uma idade mínima para a aposentadoria.

No que se refere especificamente aos fundos de pensão, a CUT comprometeu-se a envidar todos os esforços no sentido de que os seus investimentos sejam direcionados para a produção, reafirmou a importância da participação paritária dos trabalhadores na gestão dos seus recursos e posicionou-se contrariamente a retirada de patrocínio (sustentação financeira) por parte das mantenedoras. Por fim, a Central ainda reiterou a importância da equidade entre homens e mulheres no regime de previdência complementar. 


\section{QUADRO 5 - Reação Cutista à Reforma da Previdência}

\begin{tabular}{|c|c|c|}
\hline Governo FHC & Governo Lula & Governo Dilma \\
\hline - Trouxe avanços com & - Defendeu a & \\
a intervenção nos & Previdência Social & \\
Conselhos Setoriais da & Pública Universal & \\
Previdência & - Defendeu maior & - Defesa da Previdência \\
- Apresentou as & controle social sobre & Pública e Solidária. \\
Reformas Populares & Previdência & - Reconquista dos \\
- Retirou-se das & - Buscou a intervenção & direitos retirados \\
negociações com o & propositiva para & pela Reforma da \\
governo & direcionar o conteúdo & Previdência. \\
- Lutou pela & das reformas. & \\
manutenção & - Posicionou-se contra & \\
dos direitos & retirada de direitos de & \\
previdenciários. & trabalhadores. & \\
& & \\
& &
\end{tabular}

No que diz respeito à reação da CUT à reforma da previdência empreendida pelo presidente Fernando Henrique Cardoso, as resoluções dos congressos apontam que a intervenção dos sindicatos cutistas, como por exemplo, nos conselhos setoriais da previdência, trouxe avanços significativos, pois aumentou a participação e interlocução dos dirigentes sindicais com outras entidades que tratam de temas relacionados às políticas sociais.

A CUT apresenta as chamadas "reformas populares" como um conjunto de propostas alternativas às reformas de FHC, que teriam sido fruto de amplas discussões não apenas de atores internos à Central, mas com amplos setores da sociedade civil. No que tange a reforma da previdência, esta proposta teria permitido "polarizar o debate com o governo." (VI CONCUT, 1997, p. 16)

O discurso cutista também destacou a retirada da Central das negociações com o governo, pois os pontos negociados com as centrais sindicais não teriam sido contemplados no relatório final da Comissão Especial da Previdência (CESP). 
A CUT ainda afirmou a necessidade de não abandonar a luta pelo fim do fator previdenciário. Apesar de ser uma luta pontual, lutar pelo fim dessa restrição e pelos direitos trabalhistas e previdenciários seria, de uma forma geral, "parte de uma mesma luta contra a política neoliberal do imperialismo que neste caso se expressa na precarização do trabalho." (VI CONCUT, 1997, p. 37).

Já sobre as ações da CUT durante a reforma da previdência do Governo Lula, as resoluções da Central asseveram que a defesa da previdência social pública, com universalização de direitos previdenciários era uma luta histórica da Central e não deveria ser abandonada.

A defesa do controle social da previdência, a partir da gestão paritária entre governo e segurados, tanto no tocante aos gastos quantos aos rumos e determinações da previdência, também constituiria uma bandeira histórica da CUT, que deveria ser mantida independente de quem estivesse no poder.

Assim, ainda que contraditório em suas ações, o Governo Lula representava a vitória de um projeto democrático popular para o país e inaugurava um momento propício para que as reivindicações sindicais fossem ouvidas também nas questões relativas à previdência social.

Já no governo Dilma, quando a CUT toma a reforma da previdência como fato, é possível apontar uma importante mudança de posicionamento. Embora a Central se coloque na defesa da previdência pública e solidária e continue reivindicando o fim do fator previdenciário, da idade mínima para aposentadoria, da desoneração patronal, do fim da contribuição à previdência por parte dos aposentados, o período maior para a licença-gestante, a equiparação dos direitos previdenciários dos casais homossexuais aos dos casais heterossexuais e o controle social da previdência; há no discurso da CUT, por outro lado, elementos que sugerem a acomodação à retração da previdência pública e expansão da previdência privada: "A expansão da Previdência Complementar no Brasil é uma realidade." (XI CONCUT, 2012, p. 36) 


\section{À guisa de conclusão}

Todo discurso pertence a uma formação discursiva, que, por sua vez, pertence a uma formação ideológica. Cada formação ideológica tem ligações com determinadas posições de classes. Dependendo da posição do sujeito nessa posição de classe e do contexto histórico ao qual está inserido, seu discurso incorporará parte de sua subjetividade e de sua formação ideológica (ORLANDI, 2010).

Na mesma direção, Bakhtin (2006) considera que há uma ideologia oficial, propagada pelos aparelhos ideológicos de Estado, que se constitui como perspectiva dominante na concepção de mundo, presente no contexto que influencia os sujeitos e seus enunciados. Nesse sentido, Bakhtin aponta que para definir a posição do sujeito há de correlacioná-la com outras posições.

No caso do discurso da CUT o sujeito não é isolado, mas sim um conjunto de locutores, que mudaram de posição de acordo com as mudanças do governo federal. Quando da gestão de Fernando Henrique Cardoso a CUT era oposição ao governo, já a época de Luiz Inácio Lula da Silva e de Dilma Vana Rousseff a mesma constitui parte da coalizão governista. A posição que o sujeito/ locutor ocupa no contexto social e histórico e a sua formação ideológica falam juntamente com ele no seu discurso (ORLANDI, 2009), por este motivo identificamos diferenças consideráveis no discurso da CUT de acordo com o governo a que se refere.

Após a análise e categorização das resoluções dos congressos cutistas referentes aos presidentes Fernando Henrique Cardoso, Luiz Inácio Lula da Silva e Dilma Vana Rousseff, foi possível identificar sentidos muito diferentes veiculados nos discursos quando se referem aos três governos.

No caso do Governo FHC, o discurso cutista o caracteriza como representante de uma minoria, que não está disposto a ouvir os anseios populares e o responsabiliza pelo agravamento da crise social brasileira 
A insatisfação popular contra o governo de Fernando Henrique Cardoso, confirmada em diversas pesquisas de opinião, é grande e pode desaguar em poderosas manifestações populares, como ficou evidente na "Marcha dos 100 Mil a Brasília", realizada no dia 26 de agosto de 1999, sob a coordenação do movimento sindical e orientada pela palavra de ordem "Fora FHC!". A greve dos caminhoneiros, durante quatro dias (no final de julho do ano passado) ameaçou estrangular o sistema de abastecimento de mercadorias nos centros urbanos. O povo brasileiro não mais suporta as iniquidades patrocinadas por uma elite antipatriótica e subserviente ao capital estrangeiro. (VII CONCUT, 2000, p. 13)

Já no caso do Governo Lula, a CUT o caracteriza como sendo o representante das expectativas do povo brasileiro e da própria Central, como segue:

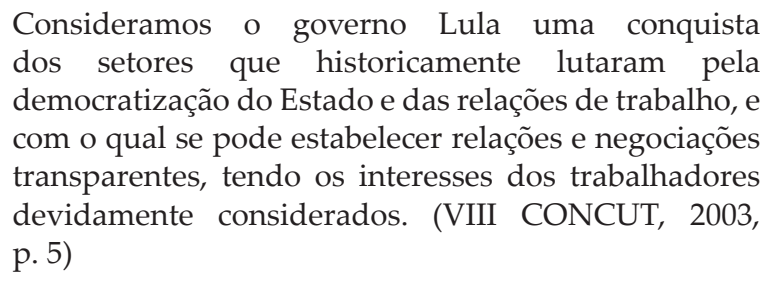

No caso do governo Dilma, o caracteriza como a continuidade da proposta anterior, porém com rupturas em alguns pontos:

Uma grande novidade do Governo Dilma Rousseff, porém, é o enfrentamento e redução do poder do capital financeiro e a afirmação quantitativa e qualitativa de um sistema financeiro público em conjunto com um Banco Central republicano (isto é, não subordinado aos bancos privados) e voltado para a defesa da moeda, contra a especulação cambial e a agiotagem (juros). (XI CONCUT, 2012, p. 15) 
Ao observarmos o modo como o discurso da CUT caracteriza as ações do Governo FHC, identificamos a tentativa de atribuir às ações deste governo a responsabilidade pelos problemas que o Brasil enfrentava, ressaltando a negatividade das ações, como se lê no trecho abaixo:

O governo FHC leva a nação brasileira ao desastre, aplicando fielmente as exigências dos excessivos acordos firmados com o FMI. Não há saída para o povo brasileiro com a permanência desse governo no poder central do nosso país, pois com essa manutenção se aprofundam o desemprego, a fome e a miséria. (VII CONCUT, 2000, p. 11)

Quando se trata do Governo Lula, o discurso cutista não se atém muito a críticas ou denúncias e sim procura ressaltar as boas ações deste governo. Há alguns registros negativos quanto a estas ações, no entanto, mesmo quando estes apontamentos ocorrem, a responsabilidade é atribuída à chamada "herança maldita" de FHC:

A atual Lei 9.478/97, herança do governo neoliberal do PSDB, impôs ao Brasil imensos prejuízos. Nos últimos dez anos, foram leiloados mais de 500 blocos de petróleo para 72 grupos econômicos, dos quais metade eram multinacionais. Essa política de licitações de blocos de petróleo e gás natural compromete a soberania nacional e o controle social sobre a utilização destes recursos tão estratégicos e determinantes para a sociedade brasileira. (X CONCUT, 2009, p. 31 e 32)

No caso do governo Dilma, a CUT também faz referência à herança deixada por Lula, principalmente na lógica da política econômica, que foi em certa medida mantida por Dilma:

Após oito anos do governo Lula, ainda é evidenciado no Estado brasileiro o peso e influência que tem o capital financeiro, núcleo das classes dominantes brasileiras. Nos anos Lula, os bancos continuaram 
acumulando recordes nas taxas de lucratividade. (XI

CONCUT, 2012, p. 15)

Parte desta herança é a realização da Copa do Mundo, e as ações do governo neste ínterim foram alvo de críticas por parte da Central, que se colocou particularmente contra a Lei Geral da Copa (Lei n.o 12.663, de 5 de junho de 2012).

As reações a cada um dos governos também foram diversas. $\mathrm{O}$ discurso em relação à gestão de $\mathrm{FHC}$ direcionou para o enfrentamento e a oposição. Como exemplo desta reação citamos o movimento "Fora FHC", proposto pela Central e destacado no documento do VII CONCUT:

O debate é necessário quanto à forma de se capturar o "elo mais fraco da corrente" que prende FHC ao governo, derrotando sua política, derrotando seus candidatos nas eleições municipais e conseguindo de fato dar concretude à bandeira já aprovada pelo movimento sindical do "Fora FHC". (VII CONCUT, 2000, p. 11)

Já o discurso em relação ao governo de Luiz Inácio Lula da Silva foi muito mais de apoio, participação e diálogo. Conforme expressa as resoluções cutistas a atuação da CUT no Governo Lula não poderia ser a mesma praticada nos governos anteriores:

Desse modo, a CUT deve dialogar com o governo no debate concreto do projeto alternativo e utilizar sua capacidade de mobilização para pressionar desde a base sindical e setores amplos da sociedade civil para que tal projeto se realize, fortalecendo-se cada vez mais diante dos governos nacional, estadual e municipal, pavimentando um campo de pressão popular para se contrapor ao brutal cerco das elites neoliberais. (VIII CONCUT, p. 5)

Sobre o Governo Dilma, visto como um cenário político favorável, a preocupação da Central foi com o estabelecimento de 
novos paradigmas, com o fortalecimento do Estado, das políticas públicas, das bases democráticas da sociedade e com a reafirmação de suas lutas históricas

Compreender que estamos no limiar de um novo período político mais favorável aos/às trabalhadores/ as e forças populares implica em novos desafios e tarefas. E significa reafirmar posições históricas de luta por um novo paradigma para as relações de trabalho no Brasil, por meio de um Sistema Democrático de Relações de Trabalho (SDRT). (XI CONCUT, 2012, p. 15)

No que tange à reforma da previdência nos três governos, o discurso da Central sobre a natureza de cada reforma e a reação a elas também apresentou diferenças significativas.

Sobre a natureza da reforma durante o Governo FHC, a Central caracterizou-a como uma reforma neoliberal, como tantas outras que o governo colocou a termo, a fim de ampliar a acumulação de capital e a abertura do país ao capital estrangeiro:

A eleição de FHC em 1994, embalada no sucesso inicial do Plano Real, acelerou a implementação das reformas neoliberais: abertura indiscriminada às importações, eliminação das políticas setoriais, privatização, reforma da previdência, sucateamento do Estado e de setores inteiros da economia, congelamento do salário do funcionalismo público e ataque às mobilizações sindicais (greve dos petroleiros de 1995). Esse conjunto de reformas amplia os espaços de acumulação de capital e, como veremos mais adiante, escancara as portas do Brasil ao grande capital estrangeiro. (VII CONCUT, 2000, p. 16)

Já sobre a reforma da previdência empreendida pelo Governo Lula, embora reconheça que houve continuidade da lógica de retirada de direitos, a CUT ressalva que, mediante a pressão dos movimentos sociais, o governo buscou romper com a proposta neoliberal de "desmonte do Estado": 


\begin{abstract}
A Reforma da Previdência no início do Governo Lula manteve a lógica de retirada de direitos dos servidores públicos, sem resolver os problemas estruturais da Previdência. Por outro lado, a pressão dos movimentos sociais e ações governamentais impuseram derrotas à lógica do Estado mínimo e da privatização de direitos. As principais iniciativas do Governo Lula na ruptura com a proposta neoliberal foram no sentido de paralisar o desmonte do Estado e de recuperar sua capacidade enquanto gestor e executor de políticas públicas. (IX CONCUT, 2006, p. 24)
\end{abstract}

A CUT afirma que a reforma da previdência do Governo Lula seguiu algumas propostas neoliberais, mas rompeu com outras, o que nos permite afirmar que o discurso da Central não a caracteriza como de natureza neoliberal, apesar de apontar alguns elementos neoliberais desta reforma. Assim, a lógica da retirada de direitos quando se trata do Governo FHC é uma prática neoliberal, mas a mesma lógica quando se refere ao Governo Lula não é caracterizada desta forma.

Já em relação ao Governo Dilma, conforme salientamos anteriormente, não promoveu uma reforma do sistema previdenciário brasileiro, mas apenas deu continuidade há algumas medidas adotadas nos governos anteriores, a CUT adotou um discurso essencialmente defensivo:
A CUT deve manter sua posição em defesa da Previdência Pública Nacional que garanta a preservação das conquistas e direitos dos trabalhadores e trabalhadoras que, após a sua vida profissional, possam usufruir do benefício da aposentadoria e/ou pensão que ajudaram a construir no transcorrer de sua vida. Necessário se faz recuperar o Controle Social sobre os recursos da Previdência. (XI CONCUT, 2012, p.36)

Sobre a reação da Central às reformas, citamos como exemplo esta passagem presente no documento do VI CONCUT, 
que expõe as condições que a levaram retirar-se das discussões sobre a reforma da previdência realizada durante o governo de FHC:

O governo, diante da resistência da sociedade, em relação ao seu projeto, abriu negociação com as Centrais Sindicais. No entanto, a maioria dos pontos que foram objetos de negociação não foi contemplada no relatório final, obrigando a CUT a se retirar das negociações e solicitar aos deputados que rejeitassem o relatório. (VI CONCUT, 1997, p. 16)

Aqui, podemos observar que, embora a Central tenha participado das discussões sobre a reforma da previdência durante o Governo FHC, quando seus objetos de negociação não foram atendidos a reação foi a de retirar-se das negociações.

Já durante o Governo Lula, mesmo levando em consideração a possibilidade de não ser atendida em suas demandas a Central não pretendia se retirar das negociações, ao contrário, afirmou a intenção de participar das negociações para disputar o conteúdo das reformas, colocando esta intenção como uma de suas ações prioritárias:

Dar continuidade ao processo de disputa sobre o conteúdo das reformas - previdenciária, tributária e fiscal, agrária e agrícola, sindical e trabalhista -, explorando as contradições presentes nas propostas em debate na sociedade e garantindo a estratégia aprovada no $8^{\text {o }}$ Concut, [...]. (VIII CONCUT, 2003, p. 80)

Assim, muito embora tenha colocado como uma de suas lutas imediatas no IX CONCUT: "Ampliar a luta pelo fim do fator previdenciário" (IXCONCUT, 2006, p. 95), mesmo quando a política previdenciária do Governo Lula mantém o fator previdenciário estabelecido na reforma de $\mathrm{FHC}$, a Central não propõe a retirada das negociações, ao contrário, considera uma pauta de destaque a sua participação nas discussões sobre a previdência, 
|131 |

Karen C. D. da Fonseca Cilla e Sidney Jard da Silva

a atuação propositiva da Central no Fórum Nacional da Previdência e no Conselho Nacional de Previdência, dando centralidade a temas fundamentais para os trabalhadores como a extinção do Fator Previdenciário para o cômputo das aposentadorias; a efetiva implantação do Nexo Técnico Previdenciário para o reconhecimento das doenças do trabalho entre outros, foram pautas de destaque na ação da Central e ramos de atividade no último período. (X CONCUT, 2009, p. 17)

Noquetangea sua reaçãoà política previdenciária doGoverno Dilma, a CUT assume uma postura ambígua, especialmente no que se refere ao regime de previdência complementar:

A expansão da Previdência Complementar no Brasil é uma realidade. Acreditando nessa possibilidade, a CUT envidará esforços no sentido de que os Fundos de Pensão de Previdência Privada, Complementares ou não, direcionem seus investimentos na produção. (XI CONCUT, 2012, p. 35).

Entretanto, também reivindica que o projeto de lei que cria o regime de previdência complementar para os servidores públicos federais (PL 1992/07) seja retirado de votação no Congresso Nacional,

Retirada de Projetos de Leis contrários aos interesses dos/as servidores/as [...] PL 1992, que trata da criação do Fundo de Pensão para os/as servidores/as públicos/ as. (XI CONCUT, 2012, p. 73)

Em síntese, como sujeito discursivo, a CUT ocupa uma posição ideológica que imprime sentidos em seu discurso. Cabe ressaltar que a posição ideológica e discursiva que o sujeito ocupa no contexto histórico não deve ser entendida como totalmente determinada, mas sim construída em atos concretos e responsáveis que criam e recriam os limites do próprio sujeito e suas interações com outrem (BAKHTIN, 2006). 
A posição da Central mudou quando passou de opositora, no caso do governo de FHC, a aliada, durante os governos de Lula e Dilma. Com esta mudança, os sentidos veiculados pela Central produziram efeitos metafóricos (ORLANDI, 2010), isto é, se deslocaram de acordo com o posicionamento discursivo e ideológico que a Central assumiu em cada momento histórico.

Neste trabalho, embasados pelos pressupostos teóricos e metodológicos da Análise de Discurso, procuramos apontar esses deslocamentos e interpretá-los. Contudo, entendemos que este esforço não esgota as possibilidades de análise, que, assim como os discursos, são inexauríveis.

\section{Bibliografia}

CENTRAL ÚNICA DOS TRABALHADORES [CUT]. VI CONCUT: resoluções. São Paulo, CUT, 1997. . VII CONCUT: resoluções. São Paulo, CUT, 2000. . VIII CONCUT: resoluções. São Paulo, CUT, 2003. . IX CONCUT: resoluções. São Paulo, CUT, 2006. . X CONCUT: resoluções. São Paulo, CUT, 2009. . XI CONCUT: resoluções. São Paulo, CUT, 2012.

BAKHTIN, M. M. (VOLOCHÍNOV, V. N.). [1929]. Marxismo e filosofia da linguagem: problemas fundamentais do método sociológico da linguagem. Tradução de Michel Lahud e Yara Frateschi Vieira, com a colaboração de Lúcia Teixeira Wisnik e Carlos Henrique D. Chagas Cruz. 12. ed. São Paulo: Hucitec, 2006.

FOUCAULT, M. A ordem do discurso. Tradução de Sírio Possenti. Ijuí (RS): Fidene, 1973.

FOUCAULT, M. Arqueologia do Saber. Tradução de Baeta Neves. Petrópolis (RJ): Vozes, 1987. 
GREGOLIN, M. R. V. et al. (Org.) Análise do Discurso: entornos do sentido. Araraquara (SP): UNESP, FCL, Laboratório Editorial; São Paulo: Cultura Acadêmica Editora, 2001.

JARDIM, M. A. C. e JARD DA SILVA, S. New Pension Legislation for Federal Public Servants in Brazil. Global Journal of HumanSocial Science, vol. 15, n.o 2, 2015, pp. 21-29.

MAINGUENEAU, D. Análise de texto de comunicação. São Paulo: Cortez, 2000.

ORLANDI, E. P. Discurso, imaginário social e conhecimento. Em Aberto, ano 14, n. 61, 1994, p.53-58.

ORLANDI, E. P. (2002) A análise de discurso e seus entremeios: notas a sua história no Brasil. Cadernos de Estudos Linguísticos, n.o 42, 2002, p.21-40.

ORLANDI, E. P. Discurso e texto: formação e circulação dos sentidos. Campinas (SP): Pontes, 2008.

ORLANDI, E. P. A linguagem e seu funcionamento: as formas do discurso. Campinas (SP): Pontes, 2009.

ORLANDI, E. P. Análise de Discurso: princípios e procedimentos. Campinas (SP): Pontes. 2010.

SARGENTINI, V. M. O. Os estudos do discurso e nossas heranças: Bakhtin, Pêcheux e Foucault. Estudos Linguísticos XXXV, São Carlos (SP), UFSCar, 2005. 